\title{
ISOLAMENTO DO Ureaplasma diversum EM MUCO VULVOVAGINAL DE VACAS LEITEIRAS REPETIDORAS DE ESTRO NO ESTADO DE ALAGOAS - BRASIL
}

\author{
(Ureaplasma diversum isolation from vaginal mucus of repeat breeders dairy cows in \\ Alagoas state - Brazil)
}

\author{
OLIVEIRA FILHO, B.D.'; PORTO, R.N.G.'; GAMBARINI, M.L.'; KUNZ, T.L.'; \\ FERRAZ, H.T. ${ }^{3}$; VIU, M.A.O.'; LOPES, D.T. ${ }^{3}$; SOUSA, A.P.F. ${ }^{4}$ \\ 1'Professor da Escola de Veterinária - UFG. Campus II, CP 131, Goiânia, Goiás, CEP 74001-970. \\ bene@vet.ufg.br; \\ ${ }^{2}$ Professor da Escola de Veterinária - Campus Avançado de Jataí - UFG; \\ ${ }^{3}$ Programa de Pós-Graduação em Ciência Animal - UFG; \\ ${ }^{4}$ Graduação em Medicina Veterinária - UFG.
}

RESUMO - O Ureaplasma diversum é um patógeno oportunista do trato genital dos bovinos que causa surtos de vulvovaginite granular, seguidos de abortamento e redução da eficiência reprodutiva do rebanho. O presente estudo foi desenvolvido com o objetivo de avaliar a relação entre a extensão e a gravidade das lesões de vulvovaginite observadas com o isolamento de Ureaplasma diversum em amostras colhidas diretamente da mucosa vulvovaginal, em fêmeas de aptidão leiteira repetidoras de estro no estado de Alagoas, Brasil. A avaliação da extensão e severidade das lesões foi feita em 93 vacas com histórico de repetição regular de estro após três ou mais inseminações artificiais, seguindo-se a seguinte metodologia de classificação: graus de 0 a 4, sendo $0=$ sem lesões; 4=lesões severas, com hemorragia e necrose. Dos 93 animais avaliados, 17,2\% apresentavam lesão grau 0; $51,61 \%$ grau $1 ; 29,03 \%$ grau $2 ; 2,16 \%$ grau 3 e nenhum animal mostrou lesão de grau 4. Foi colhido muco vulvovaginal de 24 vacas, escolhidas aleatoriamente, para processamento bacteriológico, encontrando-se $41,67 \%$ das amostras positivas para Ureaplasma diversum. $\mathrm{O}$ isolamento do agente esteve positivamente relacionado à presença de lesões na mucosa vulvovaginal, especialmente àquelas de grau 1. Os resultados deste estudo indicam que o Ureaplasma diversum deve ser considerado como agente responsável por queda na eficiência reprodutiva, promovendo retorno ao estro, provavelmente em conseqüência de mortalidade embrionária.

Palavras-chave: infertilidade, lesões, rebanho leiteiro, vulvovaginite granular.

ABSTRACT - Ureaplasma diversum is an opportunistic bacteria of the bovine genital tract and an important agent in granular vulvovaginitis, abortion, low fertility herd rate and respiratory problems in calves. The aim of this work was to study the relationship between positive cultures for Ureaplasma diversum and the extension and severity of the lesions in the vaginal mucosa of repeat breeders dairy cows in Alagoas State, Brazil. Visual evaluation were performed in 93 cows to evaluate the vaginal lesion score (VLS), classified according the lesion severity and extension ( 0 to 4 , with $0=$ no lesions, $4=$ severe inflammation and local necrosis). The VLS 1 was the most frequent $(51,61 \%)$. VLS 0 was present in $17,2 \%$ of the females, while $29,03 \%$ and $2,16 \%$ showed VLS 2 and 3 , respectively. None of the cows showed VLS 4. Vaginal swab samples were obtained from 24 females (25\%). Of them, $41,7 \%$ were positive for $U$. diversum. The presence of $U$. diversum was associated positively to VLS, especially to those cows showing vaginal lesion score 1 . The present results indicated that Ureaplasma diversum should be considered responsible for low reproductive efficiency, carrying out to repeat breeding, probably because of embryo mortality.

Key-words: dairy cattle, granular vulvovaginitis, infertility, lesions. 


\section{Introdução}

O Ureaplasma diversum pertence à família Mycoplasmataceae, da qual também fazem parte microrganismos do gênero Mycoplasma e Acholeplasma, cujas características principais são a ausência de parede celular contínua e a capacidade de hidrolisar a uréia por meio da enzima urease. É a única espécie do gênero isolada em bovinos, sendo um patógeno oportunista encontrado nas mucosas e secreções da vulva, vagina e úbere, associado à ocorrência de vulvovaginite granular, salpingite, endometrite, mastite, infertilidade, perda embrionária, abortamento, morte neonatal e no macho caracteriza-se por vesiculite seminal, balanopostite e epididimite (RAE et al., 1993; CARDOSO et al., 2000b; CHELMONSKA-SOYTA et al., 2001).

A prevalência da infecção varia de acordo com o tipo de exploração e época do ano, de 10 até $100 \%$ dos animais do rebanho, acometendo principalmente novilhas, sendo porém encontrado em animais de todas as idades, com ou sem sinais clínicos de vulvovaginite (RAE et al., 1993; LEÓN et al., 1995). Em rebanhos leiteiros a prevalência varia de 40 a $77 \%$, sendo que as nulíparas e primíparas apresentam um risco relativo 2,58 vezes maior de estarem infectados do que vacas com mais de três partos, independentemente do efeito provocado pela idade (GUSTAFSSON et al., 1995; LE GRAND et al., 1995). LÉON et al. (1995) verificam que animais da raça Jersey apresentaram maior susceptibilidade ao $U$. diversum quando comparadas à raça Holandês Preto e Branco.

No Brasil, a presença do $U$. diversum foi relatada em rebanhos com problemas reprodutivos do estado de São Paulo, onde a prevalência variou de 23 a $52,9 \%$ (CARDOSO et al., 2000a; CARDOSO et al., 2000b). CARDOSO (1998) encontrou diferença entre raças quanto a susceptibilidade ao agente, verificando que animais da raça Nelore são mais susceptíveis, seguidos pela Simental, Jersey e Holandês Preto e Branco, sendo esta última a que mostrou menor freqüência de infecção.
A infecção por $U$. diversum quando localizada na vulva, representa uma fonte constante desse organismo que, devido a abertura cervical promovida pela ação estrogênica, pode ser carreado ao útero durante o estro, onde sua presença pelo período de sete dias é suficiente para modificar o ambiente uterino prejudicando o desenvolvimento inicial do embrião (METTIFOGO, 2000). Surtos de infertilidade causados pela infecção por este microrganismo podem ou não estar associados com evidências clínicas de vulvovaginite, porém quando a fase aguda da doença predomina no rebanho, podese observar marcada redução da fertilidade (até $20 \%$ ), o que pode se prolongar pelo período de até seis meses (CARDOSO et al., 2000b; METTIFOGO, 2000).

Os mecanismos pelos quais o $U$. diversum causa infertilidade estão relacionados à interações com o sistema linforeticular, alterações na resposta imunocelular e humoral, indução e produção de substâncias citotóxicas como amônia e peroxidase, sendo que a sua habilidade de aderência à célula hospedeira é um importante fator de virulência, assim como condição essencial para o estabelecimento da infecção (MILLER et al., 1994). Este microrganismo, quando presente na tuba uterina, causa a diminuição ou o cessamento da atividade ciliar, interferindo na concepção e no desenvolvimento inicial do embrião (STALHEIM et al., 1976). Em alguns casos o $U$. diversum estimula a síntese de prostaglandina $\mathrm{F}_{2} \mathrm{a}$, potente hormônio luteolítico. Em outros casos inibe a síntese da prostaglandina $\mathrm{E}_{2}$, um dos principais hormônios relacionados ao reconhecimento materno da gestação (CHELMONSKA-SOYTA et al., 1994), contribuindo para a redução do desempenho reprodutivo pelo aumento da mortalidade embrionária.

No presente estudo, com a finalidade de se observar a relação entre a presença do microrganismo, a extensão e a gravidade das lesões encontradas na vulva, foram avaliadas fêmeas bovinas das raças Holandês Preto e Branco e Pardo Suíço, repetidoras de estro, que tinham sido previamente inseminadas pelo menos três vezes, provenientes de um rebanho que apresentava baixa eficiência reprodutiva. 
Isolamento do Ureaplasma diversum em muco vulvovaginal de vacas leiteiras repetidoras de estro no estado...

\section{Material e Métodos}

De um rebanho composto por 350 vacas das raças Holandesa Preto e Branco e Pardo Suíço, de uma propriedade localizada no município de Viçosa ( $A L)$ foram utilizadas 93 fêmeas repetidoras de estro. Todos os animais do rebanho eram servidos exclusivamente por inseminação artificial. Inicialmente os animais eram contidos no tronco, sendo examinados individualmente e o resultado anotado em ficha própria. Foram observadas a ocorrência, intensidade e severidade das lesões presentes na mucosa vulvovaginal, classificando-as em escala variando de grau zero a quatro, sendo 0 , ausência de lesões; grau 1, hiperemia leve com presença de poucas vesículas; grau 2, hiperemia moderada com vesículas; grau 3, marcada hiperemia com muitas vesículas e/ou lesões hemorrágicas; e grau 4, hiperemia intensa com presença de pústulas e/ou lesões necróticas.

Após esta avaliação foram escolhidos aleatoriamente 24 animais, dos quais obtiveram-se esfregaços da mucosa vulvovaginal, realizados após higienização seca com papel toalha descartável na região vulvar externa.

Um auxiliar mantinha os lábios vulvares da fêmea abertos, colhia-se um esfregaço da região compreendida entre o vestíbulo vaginal e a vulva, aqui designada por mucosa vulvovaginal, através da fricção de zaragatoas com ponta de algodão seca, colocadas a seguir em tubo de ensaio de plástico com tampa, contendo meio de transporte $A_{3 \times \mathrm{B}}$ (CUNHA et al., 1998) para o isolamento do Ureaplasma diversum e Mycoplasma spp.

Este material foi mantido sob refrigeração $\left(4^{\circ} \mathrm{C}\right)$ até o momento do processamento laboratorial. Chegando ao laboratório, o material foi semeado nos meios sólidos em placas de Petri, primeiramente no ágar Hayflick e posteriormente no ágar $\mathrm{U}_{10}$. $\mathrm{O}$ esfregaço era delicadamente friccionado sobre a superfície do ágar e o material mantido em incubação por até 15 dias a $37^{\circ} \mathrm{C}$ em jarras de microaerofilia, sob atmosfera de $95 \%$ de $\mathrm{N}_{2}+5 \% \mathrm{CO}_{2} \mathrm{e} \mathrm{O}_{2}$ residual, após a remoção do ar do interior da jarra $(-600 \mathrm{mmHg})$ utilizando bomba de vácuo (CARDOSO, 1998).

Para semeadura nos caldos foi retirada uma alíquota de $0,3 \mathrm{ml}$ do meio de transporte contendo o muco vaginal após ligeira agitação do mesmo, sendo realizadas três diluições decimais nos caldos Hayflick e $U_{10}$, incubadas em aerobiose por até 15 dias em estufa a $37^{\circ} \mathrm{C}$ totalizando, dessa forma, duas placas e seis tubos para leitura para cada amostra clínica colhida. Tanto as placas como os tubos foram observados diariamente por até 15 dias consecutivos. As placas foram observadas em lupa estereoscópica com aumento de $40 \mathrm{X}$, sendo o crescimento confirmado pela observação da morfologia típica das colônias quando do crescimento nos meios sólidos e através da alteração na coloração dos caldos, passando de laranja para rosa, devido à alcalinização do meio de cultura, conseqüência do consumo dos nutrientes pelos microrganismos.

A alteração na coloração do meio em decorrência da atividade da enzima urease, esta era sub-cultivada em meio sólido para confirmação do crescimento pela observação do aparecimento de colônias típicas de cada agente. As culturas consideradas negativas foram aquelas nas quais não foi possível se observar alterações do $\mathrm{pH}$ do caldo e/ou aquelas nas quais não foram evidenciadas colônias características no ágar.

\section{Resultados e Discussão}

Nos animais avaliados verificou-se a predominância de lesão do grau 1 , presente em $48(51,61 \%)$ fêmeas, seguida pela lesão grau 2, observada em $27(29,03 \%)$ animais. O grau 0 esteve presente em $16(17,2 \%)$ animais avaliados e o grau $3 \mathrm{em}$ dois (2,16\%). O grau de lesão 4 não foi observado em nenhum animal, conforme mostra a TABELA 1. 
TABELA 1 - FREQÜÊNCIA DE ANIMAIS COM DIFERENTES GRAUS DE LESÃO NA MUCOSA VULVOVAGINAL E ISOLAMENTO DE U. diversum E Mycoplasma spp EM FÊMEAS BOVINAS REPETIDORAS DE ESTRO.

\begin{tabular}{cccc}
\hline Grau de lesão & № de animais (\%) & \multicolumn{2}{c}{ № de amostras = 24 } \\
\cline { 3 - 4 } & & U. diversum $(\%)$ & Mycoplasma spp \\
\hline 0 & $16(17,2)$ & - & - \\
1 & $48(51,61)$ & $05(28,83)$ & - \\
2 & $27(29,03)$ & $04(16,66)$ & - \\
3 & $02(2,16)$ & $01(4,16)$ & - \\
4 & - & - & \\
\hline Total & $93(100,0)$ & $10(41,67)$ & \\
\hline
\end{tabular}

Das 24 amostras submetidas ao isolamento e identificação bacteriana, $10(41,67 \%)$ foram positivas para $U$. diversum. Destas amostras, cinco $(28,83 \%)$ eram oriundas de animais que apresentam lesão grau 1 , quatro (16,66\%) grau 2 e uma $(4,16 \%)$ de fêmea com lesão grau 3, não se encontrando microrganismos nas vacas com lesão grau 4.

Microrganismos do gênero Mycoplasma não foram identificados nas amostras processadas, embora AYLING et al., (2004) relataram isolamento de Mycoplasma bovigenitalium do trato reprodutivo de vacas com vulvovaginite $\mathrm{e}$ infertilidade. A presença do $U$. diversum esteve positivamente relacionada à presença de lesões na mucosa vulvovaginal, especialmente àquelas de grau 1 , mostrando 0 seu envolvimento nos distúrbios observados. A predominância de graus mais leves de lesão concorda com os relatos de RAE et al., (1993), que verificaram maior predominância de lesões grau 2 e menor número de animais portadores do grau 4, além de maior severidade das lesões em novilhas púberes do que em vacas.

Com relação à presença do $U$. diversum, os resultados deste estudo são semelhantes aos encontrados por CUNHA et al., (1998), os quais encontraram $U$. diversum em $30,87 \%$ de um total de 149 amostras de muco vulvovaginal colhido de vacas com distúrbios reprodutivos. CARDOSO (1998) verificou que isolamentos positivos para este microrganismo são mais freqüentes em animais com idade superior a 2,5 anos $(60,8 \%)$ do que em animais mais jovens $(39,1 \%)$, entretanto salientou que novilhas possuem risco relativo 1,95 vezes maior de estarem infectadas do que animais mais velhos, possivelmente pelo fato de que estes estão mais expostos ao agente em decorrência do maior tempo de contato com o microrganismo, seja através da reprodução (monta natural, inseminação artificial ou transferência de embriões), ou do contato direto com animais infectados, enquanto as novilhas apresentam maior susceptibilidade ao microrganismo, tanto pela menor resistência imunológica como pelo fato de apresentarem o epitélio vaginal do tipo colunar, que poderia facilitar a colonização pelo $U$. diversum. De acordo com CHELMONSKA-SOYTA et al., (2001) a infecção por U. diversum intensifica a produção de citocinas (IL-1) pelo embrião em desenvolvimento, seguido pelo aumento da produção de prostaglandinas, o que pode resultar em transtornos no processo de reconhecimento materno da gestação.

Em estudo semelhante, LEÓN et al., (1995) pesquisaram fatores de risco para a infecção por U. diversum em 204 vacas de 11 rebanhos leiteiros. Os autores chegaram à conclusão de que vacas mais jovens (menos de 64 meses) apresentavam um risco 2,35 vezes maior de se infectarem do que as mais velhas, e aquelas fêmeas que no momento da avaliação ainda não haviam parido ou tinham apresentado somente um parto tiveram uma probabilidade de 2,99 vezes maior do que vacas com mais de dois partos, verificando-se também que novilhas mostraram porcentagens mais altas de infecção (69\%).

De acordo com a literatura consultada, na qual são encontrados relatos que comprovam o alto grau de contágio do Ureaplasma diversum, os resultados obtidos no presente estudo mostram a importância da avaliação destas lesões, especialmente em animais pertencentes aos sistemas intensivos de produção leiteira, pois do ponto de vista econômico a sua principal via de transmissão é a venérea, durante a monta natural, 
Isolamento do Ureaplasma diversum em muco vulvovaginal de vacas leiteiras repetidoras de estro no estado...

inseminação artificial ou, até mesmo, na transferência de embriões, pois ele se adere à zona pelúcida do embrião sem alterar a sua integridade, não sendo removido após as 10 lavagens recomendadas pela Sociedade Internacional de Transferência de Embriões. O simples contato com as secreções de um animal contaminado pode representar via de contaminação por este microrganismo. Desta forma, o conhecimento da patogenia do agente torna-se imprescindível para o estabelecimento de medidas preventivas, tão necessárias para minimizar os prejuízos por ele causados sobre a eficiência reprodutiva.

\section{Conclusões}

Nas condições em que o presente estudo foi realizado, a análise dos dados permite inferir que:

A presença do Ureaplasma diversum está associada à ocorrência da síndrome vulvovaginite granular, independente do grau de lesão observado na mucosa vulvovaginal.

A infecção do rebanho por esse microrganismo pode afetar de maneira significativa a eficiência reprodutiva do rebanho, pelo aumento do número de vacas repetidoras de estro.

É necessário a realização de novos estudos com o objetivo de esclarecer a patogenia do agente e dos fatores de risco que contribuem para aumentar a severidade da lesão, visando estabelecer medidas de prevenção e controle que possam minimizar o impacto econômico desta infecção.

\section{REFERÊNCIAS}

AYLING, R.D.; BASHIRUDDIN, S.E.; NICHOLAS, R.A. Mycoplasma species and related organisms isolated from ruminants in Britain between 1990 and 2000. Veterinary Record, London, v. 155, n. 14, p. 413-416, 2004.

CARDOSO, M.V. Ureaplasma diversum e vulvovaginite granular bovina (VVG), uma provável associação. Diagnóstico através de técnicas de cultivo e reação da polimerase em cadeia. São Paulo, 1998. 53 p. Dissertação (Mestrado) - Instituto de Ciências Biomédicas, Universidade de São Paulo.
CARDOSO, M.V.; BLANCHARD, A.; FERRIS, S.; VERLENGIA, R.; TIMENETSKY, J.; CUNHA, R.A. F. D. Detection of Ureaplasma diversum in cattle using a newly developed PCR-based detection assay. Veterinary Microbiology, Amsterdan, v. 72, n. 3-4, p. 241-250, 2000a.

CARDOSO, M.V.; SCARCELLI, E.; GRASSO, L.M.P.S.; TEIXEIRA, S.R.; GENOVEZ, M.E. Ureaplasma diversum and reproductive disorder in Brazilian cows and heifers; first report. Animal Reproduction Science, Amsterdan, v. 63, n. 3-4, p. 137-143, 2000b.

CHELMONSKA-SOYTA, A.; MILLER, R.B.; RUHNKE, L.; ROSENDAL, S. Activation of murine macrophages and lymphocytes by Ureaplasma diversum. Canadian Journal of Veterinary Research, Ottawa, v. 58, n. 4, p. 275-280, 1994.

CHELMONSKA-SOYTA, A.; KATSKA, L.; KURPISZ, M.; STEFANIAK, T.; ZIMECKI. M. The effect of Ureapasma diversum activated mononuclear leukocytes on the development and interferon-tau production by bovine IVF-derived embryos. Journal of Reproduction and Immunology, Limerick, v. 51, n. 2, p. 145-158, 2001.

CUNHA, R.A.F.; CARDOSO, M.V.; BLANCHARD, A.; TIMENETSKY, J.; CORDOVA, C. Improve of the PCR technique for detection of Ureaplasma diversum in clinical samples from bovine genitalia. In: CONFERENCE OF INTERNATIONAL ORGANIZATION FOR MYCOPLASMOLOGY, 1998, Sydney. Anais... Sydney, 1998.

GUSTAFSSON, H.; BACKSTROM, G.; BOLSKE, G.; EMANUELSON, $U$. Vaginitis in dairy cows in southeast Sweden - results of a pilot study. Svensk Veterinartidning, Stockhohm, p. 69-473, 1995.

INTERNATIONAL EMBRYO TRANSFER SOCIETY. Manual of International Embryo Transfer Society. 3. ed. Savoy, 2004.

LE GRAND, D.; POUMARAT, F.; MARTEL, J.L. Genital Ureaplasma diversum infection: investigations in cattle in France. Veterinary Research, Jouy-en-Josas, v. 26, n. 1, p. 11-20, 1995.

LEÓN, B. A.; CAMPOS, E.; BOLAÑOS, H.; CABALLERO, M. Risk factors for Ureaplasma diversum infection in cattle in a tropical environment. Revista de Biologia Tropical, San José, v. 43, n. 1-3, p. 21-25, 1995.

METTIFOGO, E. Efeitos da infecção por micoplasmas no trato reprodutivo dos bovinos: diagnóstico, controle e tratamento - Revisão. Revista Brasileira de Reprodução Animal, Viçosa, v. 24, n. 2, p. 83-89, 2000. 
156

MILLER, R.; CHELMONSKA-SOYTA, A.; SMITS, B.; FOSTER, R.; ROSENDAL, S. Ureaplasma diversum as a cause of reproductive disease in cattle. Veterinary Clinics of North America: Food and Animal Practice, Philadelphia, v. 10, n. 3, p. 479490, 1994.

RAE, D.O.; CHENOWETH, P.J.; BROWN, M.B.; GENHO, P.C.; MOORE, S.A.; JACOBSEN, K.E.
Reproductive performance of beef heifers: effects of vulvo-vaginitis, Ureaplasma diversum and prebreeding antibiotic administration. Theriogenology, New York, v. 40, n. 3, p. 497-508, 1993.

STALHEIM, O.H.V.; PROCTOR, S.J.; GALLAGHER, $E$. Growth and effects of Ureaplasma diversum ( $T$ Mycoplasmas) in bovine oviductal organ cultures. Infection and Immunity, Washington, DC, v. 13, n. 3, p. 915-925,1976.

Recebido para publicação: 27/06/2005 Aprovado:

$25 / 09 / 2005$ 